\title{
Current Language Attitudes of Mainland Chinese University Students
}

\author{
Meihua Liu \\ Tsinghua University, China \\ Email: ellenlmh@gmail.com \\ Shan Zhao \\ Tsinghua University, China \\ Email: zhaoshan@tsinghua.edu.cn
}

\begin{abstract}
This paper reports on an investigation of Chinese university EFL learners' attitudes towards English and Chinese in relation to their motivation to learn the language and awareness of their ethnic identity. 302 university students answered a 22-item Language Attitudes Questionnaire and 112 of them answered four open-ended questions. Analyses of the data reveal that the participants held positive attitudes towards English, were motivated to learn the language, and valued their association with English-speaking culture and people, meanwhile considering their native language superior to English. Thus the paper concludes that the students had a sound sense of Chinese identity with an appreciation of the value of the English language.
\end{abstract}

Index Terms - language attitudes, EFL, motivation, ethnic identity

\section{INTRODUCTION}

With globalization, communication and interaction between people from various cultures and ethnics increase rapidly. Since language plays a major role in the development of social identity in general (Eastman, 1985) and ethnic identity in particular (Giles, Bourhis, \& Taylor, 1977; Giles \& Johnson, 1981, 1987), research on attitudes towards a second/foreign language (SL/FL) and the mother tongue has caught increasing attention (Ibarraran, Lasagabaster, \& Sierra, 2008; Lin \& Detaramani, 1998; Patri \& Pennington, 1998; Pennington \& Yue, 1994; Pierson, Fu, \& Lee, 1980). As Gudykunst and Schmidt (1987, p. 157) said, "language and ethnic identity are related reciprocally, i.e. language usage influences the formation of ethnic identity, but ethnic identity also influences language attitudes and language usage".

With the rapid economic development in China, Chinese people's interactions with English-speaking people from various countries have dramatically increased. Adolescents and young adults in contemporary China have a strong desire to learn English because they believe that being able to use English will help them find lucrative employment in the future or because English is necessary for tertiary education (Liu, 2006, 2007a; Yang, Liu, \& Wu, 2010). Knowing about their attitudes towards English and their mother tongue at present is important in understanding their ideas about their ethnic identity and adopting appropriate language policies in education in the future. For this purpose, the present paper aims to describe the attitudes towards English and Chinese held by Chinese university students.

\section{LITERATURE REVIEW}

Attitudes and motivation often interact with each other and play a paramount role in language learning (Dörnyei, 1990, 2001; Gardner, 1985; Gardner \& MacIntyre, 1993; Krashen, 1982; Liu, 2009; Tremblay \& Gardner, 1995). Just as Richards (1998, p. 308) claimed, "Students' attitudes towards their language course and their teacher can greatly affect their desire to learn and their classroom participation; their attitudes towards the language itself can shape their reasons for learning and the strategies they use; ...". Numerous studies (Dörnyei, 2001; Gardner, 1985; Gardner \& MacIntyre, 1993; Liu, 2009; Tremblay \& Gardner, 1995) have confirmed that positive attitudes towards a language often lead to higher motivation to learn and higher proficiency in the language.

As this research area has grown, more and more researchers turn their attention to the relationship of learners' attitudes towards a SL/FL and their mother tongue, the role of the language and their own ethnic identity (Giles et al., 1977; Giles \& Johnson, 1987; Ibarraran et al., 2008; Kwok \& Chan, 1972; Patri \& Pennington, 1998; Pennington \& Yue, 1994). Kwok and Chan (1972) found that many Hong Kong university students felt a knowledge of English to be essential to the securing of a lucrative position while disdaining the use of English except under compulsion. To investigate the relationship between language attitudes and English attainment, Pierson et al. (1980) developed a 5-point Likert Direct Attitudes Questionnaire with items related to politics, interethnic relations, career, and education. They administered the questionnaire to 466 secondary school students in Hong Kong, and found six factors were significantly related to English proficiency: 1) freedom of language choice, 2) desire to learn English, 3) lack of self-confidence in 
using English, 4) approbation for using English, 5) discomfort over Chinese speakers using English, and 6) English as a mark of education. Their study indicated that Hong Kong students saw use of English and Western values as a threat to Chinese identity. Pennington and Yue (1994) modified the Questionnaire and applied it in their research on about 285 students from non-fee paying schools in Hong Kong and found no such association. The researchers attributed the difference to sampling and methodology deployed in the two studies.

Administering Pennington and Yue's (1994) questionnaire to 250 Cantonese native speakers from Forms 5-7 from families of the middle income bracket, Axler, et al. (1998) found that: 1) the students did not feel that the use of English was associated with a threat to their ethnolinguistic identity or that English should not be the medium of instruction in Hong Kong schools, 2) the students were more willing to acknowledge the social and instrumental value of English than were their counterparts in 1980, and 3) it confirmed Pennington and Yue's (1994) finding. Thus, the researchers claimed that a change in attitudes of Hong Kong students occurred during the past two decades. Also, most of the findings were consistent with those in Patri and Pennington's (1998) investigation of the language attitudes of 40 Indian students attending middle schools in Hong Kong via the same questionnaire. Patri and Pennington (1998) found that the Indian students expressed similar but more positive attitudes towards English than did their Chinese counterparts of the generation: instrumental value of English to be used as the medium of instruction and for material success, a strong motivation to learn English, high confidence in speaking English, English being associated more with education than with other social values, English being perceived not as a threat to their native language. These suggest, according to the researchers, that the participants had a healthy sense of Indian identity and appreciated the value of English. The pattern, as believed by the researchers, could imply an acculturative style of cultural adaptation in terms of multiple group orientations.

Ibarraran et al. (2008) examined the language attitudes held by 125 local and immigrant secondary school students in the Basque Country in Spain. The results showed that both groups held rather negative attitudes towards Basque, but very positive attitudes towards Spanish. The immigrant students' attitudes toward English were far more positive than those of their local counterparts. And their attitudes towards their own languages were the most positive. Thus, the researchers claimed that a language awareness component should be included in the Basque secondary education curriculum.

Much research has also been done on Mainland Chinese EFL learners, often via Gardner's attitudes questionnaire (1985), which has revealed that Chinese students often hold positive attitudes toward English and are more instrumentally motivated to learn the language (Hao, Liu, \& Hao, 2004; Liu, 2007a; Yang et al., 2010; Zhang \& Hu, 2008). For example, 30 Chinese postgraduate students studying in America participated in Zhang and Hu's (2008) study of second language learners' attitudes towards English varieties. The results showed that the learners were positive towards the varieties of English they had been exposed to and their attitudes were not related to the understandability of the passage delivered by the speakers of the three varieties. Nevertheless, few studies on the relationship of language attitudes and ethnic identity are situated in Chinese EFL contexts. To fill in the gap, the present study sought to examine Chinese university students' attitudes towards English and Chinese in relation to their motivation to learn the language and awareness of their ethnic identity using the Language Attitudes Questionnaire adapted from Axler et al. (1998).

\section{RESEARCH DESIGN}

Participants. 302 (174 female and 128 male) students from five top-rank universities in Beijing participated in the present study. With an age range of 19 to 22, the participants came from various disciplines such as business management, civil engineering and environmental engineering.

Instrument. The Language Attitudes Questionnaire used in Axler et al. (1998) was modified to better fit the present situation. The original item 1 "It is a good thing to have English as the main official language of Hong Kong" was changed to be "It is a good thing that English is enjoying a high status in Mainland China" since English is not an official language of the country; and the original item 15 "My history, geography, and mathematics textbooks should be written or translated into Chinese" was deleted since it is not true in the present situation. Thus resulted in the 22 -item 5-point Likert questionnaire ranging from " $1=$ Absolutely Disagree" to " 5 = Absolutely Agree". And the items could be grouped into six categories, as done in Patri and Pennington (1998): (1) support of the high status of English (items 1, 6, 17, 21), (2) personal commitment to English (items 15, 19), 3) intrinsic/integrative motivation (items 7, 9, 11, 18, 22), (4) confidence in using English (items 8, 16), (5) association of English with education (items 2, 4, 13, and (6) ethnic identity (items 3, 5, 10, 12, 14, 20).

To allow for the possibility of 'cross-cultural accommodation' (Bond \& Yang, 1982), the questionnaire was worded in both mandarin Chinese and English, as done in Axler et al. (1998). In addition, four open-ended questions were added: 1) what do you think of the status of English in Mainland China? 2) Is it helpful to the development of China if the status of English is raised? How? 3) Which of the two do you think is more important to a Chinese, to learn English well or Chinese well? Why? and 4) what do you think of the present enthusiasm for learning English in Mainland China?

Procedure. About 400 students in five universities in Beijing were invited to complete the questionnaire online in 10 minutes and answer the online open-ended questions in 10 minutes as well if they were willing to. Finally, 302 collected questionnaires were valid for further analyses; and 112 students answered all the four open-ended questions. 
Data analysis. The survey data were analyzed in terms of mean, standard deviation and rank to reveal the general pattern of the students' attitudes towards English and Chinese. Then, within-group patterns were further examined. The responses to the open-ended questions were analyzed according to the themes that occurred, with frequency and percentage being counted to indicate, for example, how many participants believed that Chinese was superior to English and how many held that learning English was helpful to China's development. Results of these qualitative data were integrated into the discussion of those of quantitative data.

\section{RESULTS AND DISCUSSION}

\section{A. Overall Pattern}

To reveal the overall pattern of the students' attitudes towards English and Chinese, the mean and standard deviation of each item in the questionnaire were calculated. From the means, the items were placed in rank order. The results are presented in Table 1.

TABLE 1:

LANGUAGE ATTITUDES QUESTIONNAIRE

Responses for Chinese University Students $(\mathrm{N}=302)$

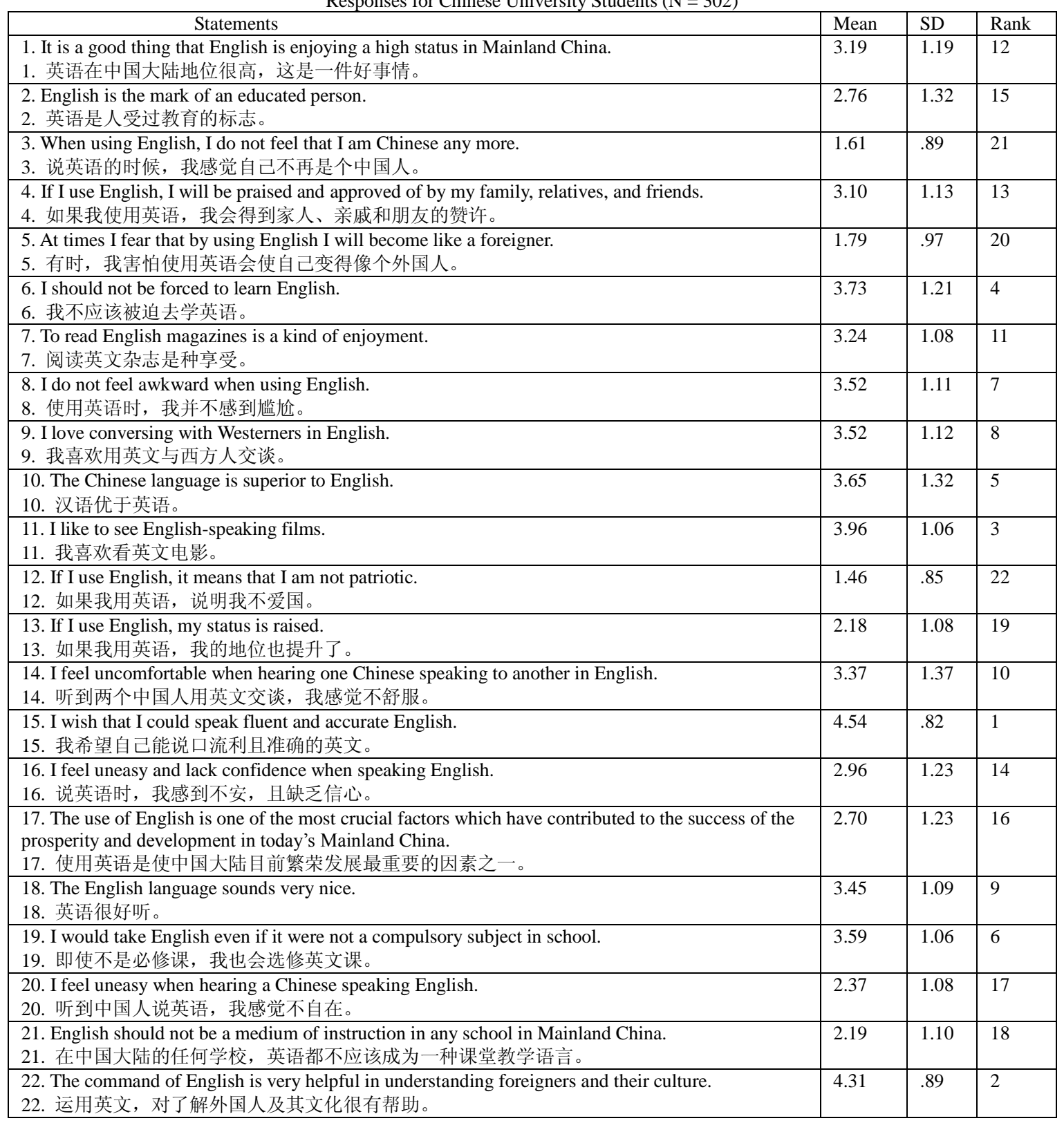

Based on the means and rank orders, the two highest ranking items were 15 and 22 with a mean of more than 4.30 , indicating strong agreement. With a mean range of 3.10 to 3.96 , items $11,6,10,19,8,9,18,14$, 7, 1 , and 4 were top-ranking items, indicating moderate agreement. Items 16, 2, 17, 20, 21, and 13 (mean range: 2.18-2.96) ranked low 
in the questionnaire, implying moderate disagreement; and the remaining items (items 3, 5, and 12) scored below 1.79, reflective of strong disagreement. The responses show that the participants strongly wished to be fluent and accurate users of English and strongly believed the command of English to be helpful in understanding foreigners and their culture. Meanwhile, they moderately agreed that it was a good thing for English to enjoy a high status in Mainland China, that a good user of English would be praised, that they loved to use English, that Chinese was superior to English, that English was nice, and that they would learn English even if not required. Nevertheless, they strongly denied the feeling of being not Chinese or patriotic when using English. These results were largely consistent with those in Axler et al.'s (1998) study of Hong Kong secondary school students but only moderately conformant with those in Patri and Pennington's (1998) of Indian secondary school students in Hong Kong. Like their younger peers in Hong Kong (Axler et al., 1998; Patri \& Pennington, 1998), these university participants did not feel that the use of English was associated with a threat to their ethnolinguistic identity, while they desired to learn and use the language well and were willing to acknowledge the social and instrumental value of the language.

\section{B. Within-group Patterns}

The within-group patterns are described in the six categories, as described by Pierson et al. (1980) and done in Patri and Pennington (1998).

\section{Support of status of English}

Four items (items 1, 6, 17 and 21) were included in this category. Responses to these items (mean range: 2.70-3.73 as shown in Table 1) suggest that these participants were generally supportive of the high status of English (item 1) and of English as the medium of instruction (item 21) in Mainland China, although they generally disagreed that the use of English greatly contributed to the prosperity and development of today's China (item 17) and more than half of them believed they should not be forced to learn the language (item 6).

This result is generally consistent with the responses to the open-ended questions. Among the 112 collected answers, the status of English in Mainland China was believed to be low by $13(11.6 \%)$, ordinary by 4 (3.6\%), and high by 95 $(84.8 \%)$ of the participants. Among the 95 respondents who maintained that English enjoyed a high status in Mainland China, $26(27.4 \%)$ held that it surpassed Chinese in importance, $9(9.5 \%)$ believed it was as important as the latter, and $60(63.2 \%)$ claimed that it was inferior to Chinese. As to the benefits English could bring to China, $2(1.8 \%)$ of these respondents denied any use of English, 4 (3.6\%) believed it to be both beneficial and detrimental, and $2(1.8 \%)$ believed it to be harmful to China in the long run mainly due to brain drain. The majority (102/91.1\%) maintained that English contributed to the development in China in international communication, global cooperation, intercultural exchange, economic development, education, knowledge expansion and upgrading, and business. They held that because of the use of English, China had came to know the world better and make herself better understood by the world as well.

2. Personal commitment to English

This group had two items: 15 (mean $=4.54)$ and 19 (mean $=3.59)$, the positive responses to which show a strong orientation to English, implying that the students not only desired to know English well but also were motivated to take actions to improve their English, as reported in several studies of similar students (Axler et al., 1998; Liu, 2007a; Hao et al., 2004; Yang et al., 2010).

\section{Intrinsic/Integrative motivation}

Items 7, 9, 11, 18, and 22 were associated with intrinsic and integrative motivation to learn the English language (Deci \& Ryan, 1985; Gardner, 1985; Patri \& Pennington, 1998; Yang et al., 2010). The fairly positive responses to these items, with means ranging from 3.24 to 4.31 as reported in Table 1, demonstrate that the respondents agreed that it was an enjoyment to read English magazines, to watch English-speaking films, and to converse with westerners in English. This indicates that the participants learned English for its own sake rather than only for fulfilling instrumental goals or the expectations of others, slightly different from the finding in Liu (2007a) and Yang et al. (2010). This might be accounted for by the fact that all the participants were studying in Beijing where students normally have more access and exposure to English as well as more opportunities to use the language.

4. Confidence in using English

This category consisted of two items: $8($ mean $=3.52)$ and $16($ mean $=2.96)$. The responses to these two items were implicative of moderate confidence in speaking English, which is both cause and effect of frequent use (Balla \& Pennington, 1996; Lai, 1993; Liu, 2006, 2007b). This might be because English, as a foreign language, is still rarely used in the students' daily life despite their more exposure and access to the language in Beijing.

5. Association of English with education

This cluster had three items: 2 (mean $=2.76), 4($ mean $=3.10)$, and 13 (mean $=2.18)$. The responses to these items indicate that English was less associated with education for these students than for their peers in Hong Kong reported in Axler et al. (1998) and Patri and Pennington (1998). They did not believe that English was the mark of education or that one's status was raised if she/he used English. It seems that these participants were fairly aware of the status of English as a foreign language in Mainland China and the predominant role and use of Chinese as the majority language, as happened in Ibarraran et al. (2008).

6. Ethnic identity

This category included six items: $3($ mean $=1.61), 5($ mean $=1.79), 10($ mean $=3.65), 12($ mean $=1.46), 14($ mean $=$ $3.37)$, and $20($ mean $=2.37)$. The responses to these items show that the respondents generally held the view that their 
mother tongue (Chinese) was superior to English and felt uncomfortable when hearing one Chinese speaking to another in English. Meanwhile, they vetoed the other four items indicating the denial of Chinese identity or being patriotic by using English. This finding is further supported by their responses to the open-ended questions. Except that 3 (2.7\%) and $30(26.8 \%)$ of the 112 respondents believed that English was more important and that English was as important as Chinese respectively, 79 (70.5\%) of them maintained that Chinese, as the mother tongue, was definitely (much) more important than English. Hence, when asked to comment on the present enthusiasm in learning English, although 89 (79.5\%) of them considered it to be meaningful, they, as well as the rest of the 112 respondents, held that not every Chinese should learn English, that Chinese learners should not spend too much energy on the language, and that Chinese should never be ignored at any time. All these clearly manifest that English was not seen as a threat to their own identity by the participants, as found in Axler et al. (1998) and Patri \& Pennington (1998). As claimed by Hall and Gudykunst (1987), competence in an out-group language may increase with strong in-group identification. As all the participants were native Chinese studying in Beijing, English was hence unlikely to be perceived as a threat to their native language or their ethnic identity.

\section{CONCLUSION}

As illustrated above, the present study reveals that the participants were positively oriented towards English, were motivated to learn the language, and valued their association with English-speaking culture and people. Nevertheless, they considered their native language superior to English and were not praised by their families for being able to associate with English culture and language, as found in Patri and Pennington's (1998) study of Indians in Hong Kong. This pattern of attitudes illustrates a sound sense of Chinese identity with an appreciation of the value of the English language, as found in Ibarraran et al. (2008) and Patri and Pennington (1998). These results confirm that there is a communal social identity that involves support for and knowledge of English in China. They also imply that the present policies concerning English education in China is appropriate.

Meanwhile, it is worth noting that all the participants of the present study came from Beijing. Their attitudes towards English might be more positive since they normally had more access and exposure to the language and had more opportunities to use it. A different picture might be revealed if university students in other parts of China were involved. The pattern may also be different to younger students such as middle school students. Thus, future studies are called for to compare the attitudes towards English and Chinese held by different groups of Chinese students with diverse backgrounds.

\section{REFERENCES}

[1] Axler, M., Yang, A., \& Stevens, T. (1998). Current language attitudes of Hong Kong Chinese adolescents and young adults. In M. C. Pennington (Ed.), Language in Hong Kong at Century's end (pp. 329-338). Hong Kong: Hong Kong University Press.

[2] Balla, J., \& Pennington, M. C. (1996). The perception of English-medium instruction by tertiary-level vocational students in Hong Kong. Education Research Journal, 24, 131-153.

[3] Bond, M. H., \& Yang, K. (1982). Ethnic affirmation versus cross-cultural accommodation. Journal of Cross-cultural Psychology, 13, 169-185.

[4] Deci, E. L., \& Ryan, R. M. (1985). Intrinsic motivation and self-determination in human behavior. New York: Plenum Press.

[5] Dörynei, Z. (1990). Conceptualizing motivation in foreign language learning. Language Learning, 40, 45-78.

[6] Dörnyei, Z. (2001). Teaching and researching motivation. Longman: Pearson Education Limited.

[7] Eastman, C. (1985). Establishing social identity through language use. Journal of Language and Social Psychology, 4, 1-20.

[8] Gardner, R. C. (1985). Social psychology and second language learning: the role of attitudes and motivation. London: Edward Arnold.

[9] Gardner, R. C., \& MacIntyre, P. D. (1993). A student's contributions to second language learning. Part II: affective variables. Language Learning, 26, 1-11.

[10] Giles, H., Bourhis, R. Y., \& Taylor, D. M. (1977). Towards a theory of language in ethnic group relations. In H. Giles (Ed.), Language, ethnicity and intergroup relations (pp. 307-348). London: Academic Press.

[11] Giles, H. \& Johnson, P. (1981). The role of language in ethnic group relations. In J. Turner and H. Giles (Eds.), Intergroup behavior (pp. 199-243). Oxford: Basil Blackwell.

[12] Giles, H., \& Johnson, P. (1987). Ethnolinguistic identity theory: a social psychological approach to language maintenance. International Journal of the Sociology of Language, 68, 69-99.

[13] Gudykunst, W. B., \& Schmidt, K. L. (1987). Language and ethnic identity: an overview and prologue. Journal of Language and Social Psychology, 5, 291-301.

[14] Hall, B. J., \& Gudykunst, W. B. (1987). Research note: the intergroup theory of second language ability. Journal of Language and Social Psychology, 5, 291-301.

[15] Hao, M., Liu, M., and Hao, R. P. (2004). An Empirical Study on Anxiety and Motivation in English as a Foreign Language. Asian Journal of English Language Teaching, 14, 89-104.

[16] Ibarraran, A., Lasagabaster, D., \& Sierra, J. M. (2008). Multilingualism and language attitudes: local versus immigrant students' perceptions. Language Awareness, 17, 326-341.

[17] Krashen, S. D. (1982). Principles and practices of second language acquisition. Oxford: Pergamon Press.

[18] Kwok, H., \& Chan, M. (1972). Where the twain do meet: a preliminary study of the language habits of university undergraduates in Hong Kong. General Linguistics, 12, 63-82. 
[19] Lai, C. (1993). Communication failure in the classroom: an exploration of causes. RELC Journal, 25, 99-129.

[20] Lin, A., \& Detaramani, C. (1998). By carrot and by rod: extrinsic motivation and English attainment of tertiary students in Hong Kong. In M. C. Pennington (Ed.), Language in Hong Kong at Century's end (pp. 329-338). Hong Kong: Hong Kong University Press.

[21] Liu, M. (2006). Anxiety in Chinese EFL Students at Different Proficiency Levels. System, 34, 301-316.

[22] Liu, M. (2007a). Chinese students' motivation to learn English at the tertiary level. Asian EFL Journal, 9, 126-146.

[23] Liu, M. (2007b). Anxiety in oral English classrooms: a case study in China. Indonesian Journal of English Language Teaching, $3,119-137$.

[24] Liu, M. (2009). Reticence and anxiety in oral English lessons. Berne: Peter Lang AG.

[25] Patri, M., \& Pennington, M. C. (1998). Acculturation to English by an ethnic minority: the language attitudes of Indian adolescents in a Hong Kong International school. In M. C. Pennington (Ed.), Language in Hong Kong at Century's end (pp. 329-338). Hong Kong: Hong Kong University Press.

[26] Pennington, M. C., \& Yue, F. (1994). English and Chinese in Hong Kong: pre-1997 language attitudes. World Englishes, 13, $1-20$.

[27] Pierson, H. D., Fu, G. S., \& Lee, S. Y. (1980). An analysis of the relationship between language attitudes and English attainment of secondary school students in Hong Kong. Language Learning, 30, 289-316.

[28] Richards, S. (1998). Learning English in Hong Kong: making connections between motivation, language use, and strategy choice. In M. C. Pennington (Ed.), Language in Hong Kong at Century's end (pp. 329-338). Hong Kong: Hong Kong University Press.

[29] Tremblay, P. F., \& Gardner, R. C. (1995). Expanding the motivation construct in language learning. Modern Language Journal, 79, 505-518.

[30] Yang, L., Liu, M., \& Wu, W. (2010). An investigation of Chinese undergraduate non-English majors' English learning motivation. In Z. Lv, W. Zhang, \& P. Adams (Eds.), ELT at tertiary level in Asian context: issues and researches (pp. 48-62). Beijing: Tsinghua University.

[31] Zhang, W., \& Hu, G. (2008). Research note: second language learners' attitudes towards English varieties. Language Awareness, $17,342-347$.

Meihua Liu is associate professor of English at the Department of Foreign Languages and Literatures, Tsinghua University, China. Her research interests mainly include EFL teaching and learning in the Chinese context, individual differences, anxiety and reticence, and EFL writing.

Shan Zhao is associate professor of English at the Department of Foreign Languages and Literatures, Tsinghua University, China. Her major research interests include EFL teaching and learning and EFL writing. 